\title{
Transit Oriented Development, an Update about EU and US Approach
}

\author{
Anna Laura Petrucci \\ Dar Al Uloom University \\ Mizan St, 13314 Riyadh, KSA \\ apetrucci@dau.edu.sa
}

\begin{abstract}
After 25 years from its first formulation, Transit Oriented Development (T.O.D.) is going to be applied in several metropolis of east and middle east, where new metro lines are under implementation; for some of those the public transportation is arriving for the first time, or is going to be massively implemented, as in Saudi Arabia. Beside developing infrastructures for public transportation, the new metro projects are going to bring a new improvement in the urban structure, from a mono-centric and autooriented, into a pedestrian-friendly and transit-oriented metropolis. The success of the new Metro will pass by the successful development of the involved districts as T.O.D. neighbourhoods. This is going to be successful only working by procedural strategies on strongly integrated methodologies for analysis, design, maintenance as post production and the management of the whole process, before than just going for the usual planning and urban or architectural design projects. Starting from the guidelines of Transit Oriented Development Institutes and the several case studies in the USA, the research will extend into the most successful urban development strategies in Europe, through direct experience and monitoring of the results for the selected projects within the last 15 years.
\end{abstract}

Keywords: Urban Development, T.O.D., Good Practices, Integrated Project, Rehabilitation, Participate Process.

\section{Introduction}

Transit Oriented Development (T.O.D.) was defined for the first time in 1993 by Calthorpe as inverted tendency to the urban sprawl, which characterized the urban growth of the American cities since the beginning of the 20th Century, when the established model for the Garden City moved into suburbs. This model was based on a car-centred development, where the private transportation was the favourite one by the middle class; in fact in the past century, the 51\% of the USA housing were built in those suburbs and located sometimes almost $200 \mathrm{~km}$ far away from the urban centre those are related to. T.O.D. had a boom in the USA as tool to control the extreme and no longer manageable urban sprawl, considering the rail stations as centre for a new urban densification, and strategic gathering points for the collectivity, including new activities and functional mix as attractors for a new polycentric and more sustainable urban development.

In a recent book, the Italian urban planner and theorist Bernardo Secchi is highlighting how, according to the most recent reports, this tendency was fully changed, so that if in the 90 's only the $7 \%$ of New York's construction licences were released in the city centre, and the $70 \%$ in the suburbs, after 20 years the percentage were completely inverted. Same phenomenon were registered in Chicago, where the urban Loop -the central district- become the triple within the last decade.

Interviews to the American Millenials -around 80 million people- demonstrated that almost the $80 \%$ of them prefers to live in the urban areas, and in the $68 \%$ of the cases they even don't have driving licence. Same trend was registered for tertiary business companies so as about the malls, with a growing up of the Walmart's Neighborhood Markets being usually one fourth in surface than the usual malls. Suburbs in fact changed the social level of their inhabitants, which are nowadays mainly from poor or very low income condition. Secchi stresses the main role or urban design in managing the social changes and the need of returning back to a human cantered planning, as the city can be tool for exclusion or otherwise for social inclusion. Traditionally, in fact, the city was deputy space for integration, where social and cultural diversity melt together creating a new shared identity, were first then anywhere else innovation and technology were going to be applied. The growth of a culture in sustainable development, the difficult management of a no longer planned sprawl, turned the centre of cultural debate back on the City, not only in the US and Europe, but all over the world. T.O.D. is extensive applied in several cities being going through a new phase of expansion, so as in new development of the city centre. This is the case of the most cities in India, in far and middle east: Singapore, India, Saudi Arabia where T.O.D. 
focuses development in transit-supported locations, linking the transit directly with the land use, and bringing people together with jobs and services. There is not an universally accepted definition for T.O.D., most of these definitions include moderate to high to density, pedestrian orientation, mixed use, and transit connection. In Europe for instance the terms is rarely used, despite the same concepts are almost always applied, being the urban mix and the pedestrians approach to the city centre a long-lasting tradition and eventually the characteristic itself for the historical main districts.

\section{Urban Development Cases as T.O.D. in the US}

In the US consistent funds have been designated to T.O.D. in several neighbourhood of different states. Among the American cases it's worth to mention those were the development of a T.O.D. happened within an already structured district, as the case of Portland. Here extra funding were used since 2011 to start public-private project financing and redirecting as T.O.D. districts already planned areas to be re-developed. In Portland, the evaluating factors are related to market strength and urban form in order to group the region's station areas and frequent bus corridors into three categories. The titles of those: plan \& partner, catalyze \& connect, infill \& enhance reflect the types of investments that are selected as the most appropriate to help the corresponding station areas and corridors to be developed for more intensive T.O.D.

The reported tab shows how strong is the public and private intervention for each selected strategy in terms of investment and management. And the focus on T.O.D. as continuing, long-lasting program. This pragmatic approach also serves the local agencies for the further implementation of the projects as, among those, in the case of Denver. On regional scale main factors of development are: the transit connectivity as proximity to Light Rail and/or bus; the pedestrian and bicycle connectivity as intersections and sidewalks densities, Proximity to Trails, Low Traffic Streets, Dedicated Bicycle Lanes, Overall Pedestrian and Bicycle Safety at Intersection Crossings. Land Use Characteristics are defined as Presence of Key Retail and of Grocery Stores, Population Density, Building Height and Massing, Vegetation. To compile these many factors into a single, meaningful, and measurable indicator of urban form and "T.O.D. Readiness", the Metro staff created a GIS Model that quantifies each of the above, weighs their impact on T.O.D. potential, and overlays them into a single measure. A simpler version of the model clusters the above characteristics into five categories, called the "5 P's:" directly mutated from the classic Marketing approach: People, as the number of residents and workers and related reduced auto trips ; Places: as areas with commercial urban amenities such as restaurants, grocers, and specialty retail not only allow residents to complete daily activities without getting in a car, and improving factor for the likelihood of higher density development by increasing residential land values; Physical Form: preferring the small block sizes which promotes more compact development and walkability; Performance in quality and quantity for bus and rail service; Pedestrian/Bicycle Connectivity as accessibility to sidewalks and low stress bikeways to walk or cycle to transit and neighbourhood destinations. 
Table 1: Sample of T.O.D.I. Evaluation Matrix (source: http://cT.O.D..org/portal/Portland-Metros-T.O.D.-Strategic-Plan).

\begin{tabular}{|c|c|c|c|c|c|c|c|c|c|c|c|c|c|c|}
\hline & \multicolumn{4}{|c|}{ Longer-Term Strategies } & \multicolumn{7}{|c|}{$\langle-\cdots$ Continuum of TOD Investment Strategies ..... } & \multicolumn{3}{|c|}{ Shorter-Term Strategies } \\
\hline & 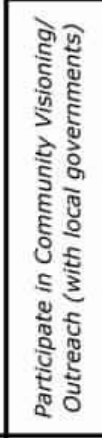 & 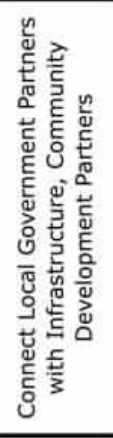 & 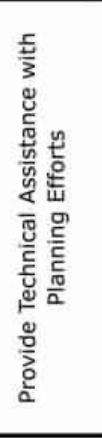 & 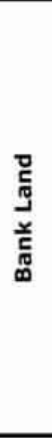 & 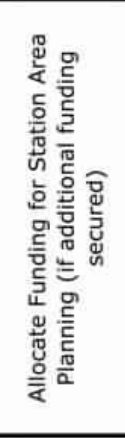 & 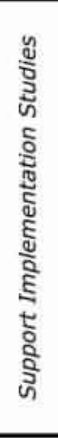 & 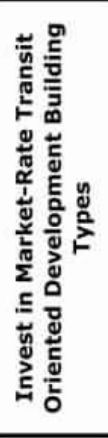 & 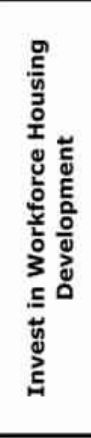 & 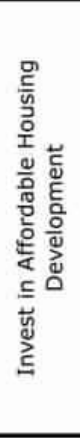 & 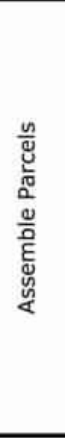 & 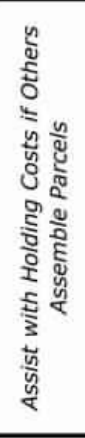 & 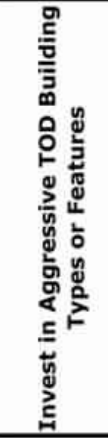 & 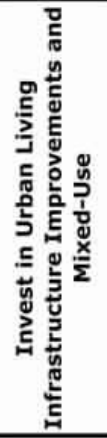 & 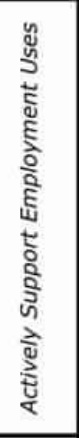 \\
\hline \multirow{3}{*}{ 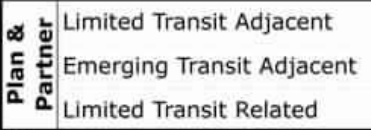 } & 0 & 0 & $x$ & C & $\mathrm{x}$ & & & & & & & & & c \\
\hline & o & o & $x$ & c & $\mathrm{x}$ & & & & c & & & & & c \\
\hline & 0 & 0 & $x$ & C & $x$ & $x$ & $x$ & $x$ & & & & & & C \\
\hline \multirow{3}{*}{ 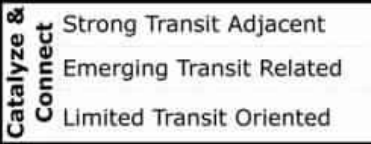 } & 0 & 0 & $x$ & & $x$ & $\mathrm{x}$ & $x$ & & & & & & & \\
\hline & 0 & 0 & $x$ & & $x$ & $\mathrm{x}$ & $x$ & $x$ & c & c & c & & c & c \\
\hline & 0 & & $x$ & C & $x$ & $x$ & $x$ & $x$ & & & & & C & C \\
\hline \multirow{3}{*}{ 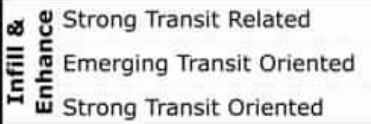 } & & 0 & & & $x$ & $x$ & $x$ & & $x$ & C & C & $x$ & C & c \\
\hline & & & & & & $x$ & $x$ & $x$ & c & C & C & & C & c \\
\hline & & & & & & & & & $x$ & C & C & $x$ & & C \\
\hline
\end{tabular}

Most of the other available reported cases, even when praised ones by institutional recognition, lack of the sense of the city. Those are in fact mainly new suburban expansion, where the principle of T.O.D. were literally -and certain wellapplied. This is the case of the T.O.D. awarded developments for Paseo de la Riviera, in Florida, a new proposed new mixed-use project located directly across from the University metro station. The project consists of a hotel, a residential tower, and ground floor retail and cafes surrounding a car-free central public space. An exemplary project which meets the general goals and objectives of T.O.D. and its certification, as the creation of an urban, walkable, mixed-use pattern of development. This creates spatial definition, improves the pedestrian experience, hiding at the same time the parking lots; all in a well functioning blend on the low-scale neighbourhood located directly behind. Another awarded case is the Del Mar Station in California, on the metro line which connected Los Angeles and Pasadena, on the edge of Pasadena's downtown. The project is really massive, offering to the city about 350 apartments, of them $15 \%$ as affordable units, and a network of $2000 \mathrm{sqm}$ of commercial areas thin interconnected, so as 1200 hidden car parking slots achieving an high density without for it compromising the human scale and well reconnecting to the existing neighbourhood. A remarkably high density is achieved while maintaining a human-scale, and the rich architecture reflects a blend of traditional yet contemporary style in a vibrant interaction between architecture and urban design with the creative use of building types, styles, and detailing.

\section{Urban Development Cases as T.O.D. in EU}

Much more complex is the approach required by the European cities, were the concept of T.O.D. itself never really get openly declared even if surely applied, just being defined as urbanism. This change was well reported by L.Bertolli, C. Curtis, J. L. Renne, who listed the synergic effect of different factors grouped into: technological and institutional innovation, public policies and discourses and the spontaneous development on the demand side. Main starting factors for changing the role of the main stations were the infrastructural innovation, requiring switch and interconnection with the new system of High-Speed Railway (HSR) network; the expansion of regional and urban rail systems and to the 
privatization of main rail companies. Following it, came the improvement of the existing urban-regional rail-based systems, and its integration with the metropolitan lines to facilitate the connection with the metropolitan suburbs, which are strongly related to multi-modal accessibility. New rails link airports and cities, as shown by extensive developments and plans along such connections in cities as Copenhagen, Stockholm, Helsinki, and Zürich. The needed logistic reorganization of the stations created a large amount of rest areas and with it an interesting economic opportunity of self financing, to compensate the expensive public service offered by the rail companies. These changes brought the Stations back to the Beginning of XX Century, making these a sort of modern Wunderkammern were innovative technology in motion meets the last discoveries on the market. Stations went back to their original iconic symbolism embracing the essence of contemporary city planning, offering gathering, services and commerce. A significant project is the Congress Centre at Stockholm Central Station in 2010,connected to the airport with a 20 minutes train trip and so close to the City House and to the bay. A strategic location for a project done by different blocks, hosting a congress and concert hall for around 300 people, a 400-rooms hotel and a magnificent view to the city. Other case to be mentioned is the extension of the Holland Spoor Station in The Hague, a piece of the perfect puzzle for multi-modal transportation in the whole Netherland, European pioneer on this issue. The privatization of the Railways finally plays a main role, making the Transit Oriented Development as the direct cause for what may be called as a Market Oriented Development (M.O.D.). In fact the main stations and their border areas, which were traditionally used for industrial purposes, get freed up for new activities. In Italy, for example, a wide process of rehabilitation of the most important train station happened by Grandi Stazioni, private real estate company created ad hoc by the Italian railway since 2000. Its commitment consists in updating the extremely old fashioned main rail stations up to the level of international airports, with elegant shopping and food courts. This real estate operation includes usually the capitalizing upon land premiums by selling land around stations, so as by renting out space inside stations. The most dramatic change has been registered in Roma Termini and Napoli, the most crowded and unsafe places for passengers before the completion of the renewal projects. A missed opportunity on other hands is represented by Roma Tiburtina, where the complex project was not finalized on both sides of the planned commercial gallery, not allowing the inclusion of the surrounding areas the related changes in the district so as any upgrade for the level of security within and around the station. As matter of fact that the process should be fully developed and integrated to be effective. All those development projects respond to the more general dynamism of the contemporary society and it's root in relatively autonomous trends on the demand side. Mobility allows wider spatially distributed activity locations which could be functionally connected due to a short travel time, rather than distance which could newly determines the functional extent of cities; allowing for example the concentration of big malls and major franchise brands habiting the stations, so as peripheral areas directly connected to the regional train. This is the case of London, Paris, Leipzig, Cologne, Berlin, Zürich, Basel, or Antwerp, so as the opening of major new conglomerates of facilities at peripheral stations, such as at Rotterdam Alexander and Amsterdam Bijlmer Arena Utrecht Central Station in the Netherlands or Lille in France.

The interconnection should not necessarily be commercial, but eventually related to the core vocation of the city, as for instance testified by the breath-taking new public spaces at Madrid Atocha Station or the rich cultural programme of Kassel Bahnhof. The integrated development of railway networks and land around the nodes of those networks is seen as a way towards a more public transport and non-motorized modes-oriented, concentrated urbanization pattern. The arguments for this shift are not merely environmental (reduction of pollution, greenhouse emissions, land consumption, etc.); many local governments and citizens also see it as a condition for the development of a much needed mobility alternative for congested metropolises rapidly approaching traffic gridlock. These strategies are in fact less focused on single stations and more on developing a polycentric network of station areas of different sizes and functions in an urban regional context; the most successful the long-standing and continuously revamped public transport and land-use development strategies of such cities as Copenhagen, Stockholm, and the 'Stedenbaan' project in the Rotterdam-The Hague area in the Netherlands, were bikes and other alternative transportation system are rooted into the local culture.

\section{T.O.D. Guidelines and Standards}

After 25 years from the first definition of T.O.D., it still constitutes an exception in auto-dependent countries, such as the United States, where less than 5\% of urban districts can be considered walkable and/or T.O.D., despite market studies indicate that $30-50 \%$ of Americans would choose a T.O.D., if such a product existed in the marketplace. A recent study is reporting that nearly $80 \%$ of those in Generation $Y$ desire to live in an urban core because they prefer mixed use and well 
connected neighbourhoods, also Baby Boomers share the same desires as Generation $Y$ targeting a walkable and transitserved communities as they retire. The reason why T.O.D. is, or would be, the preferred choice, is that it's targeting a better quality of urban life allowing, at least potentially, a degree of human interaction in the public domain - or 'urbanity'- which is difficult, if not impossible to achieve in much more socially segregated car-dependent urban environments.

Two main institutions, the Transit Oriented Development Institute (T.O.D.I.) and the Institute for Transportation Development Policy (I.T.D.P.), have produced the most consistent guidelines about T.O.D. from the two main points of view: the transportation and the urban development. Founded in 1985, the I.T.D.P. has become a leading organization in promoting environmentally sustainable and equitable transportation policies with worldwide projects under the sponsorship of the main global NGO; it started in the U.S. to offer valid alternatives to costly and environmentally damaging models of dependence on the private automobile. Their knowledge was exported to developing countries to implement new transportation Transit Oriented Development projects as bus rapid transit (BRT) systems, and planning facilities for bicycles and pedestrians. Further programs include traffic demand management (TDM), parking regulations, and the revitalization of city centres.

The Institute for Transportation Development Policy (I.T.D.P.) also developed a T.O.D. Standard system, as tool to help shape and assess urban development. It focuses on maximizing the benefits of public transit and non-motorized mobility while placing the emphasis firmly back on the users: people. This is based on eight core principles of urban design and land use, each supported by specific performance objectives and easily measurable indicators. The Standard's outlines are addressed to a broad range of technical and non-technical audiences including policy makers, planners, city officials, developers, architects, urban designers, landscape designers, civil engineers, civil society organizations, offering a way to quickly evaluate the planning and design components that are key to successful T.O.D. making possible to target three different levels of achievement, as gold, silver and bronze certification. Those standards: transit, walk, cycle, mix, densify, compact, shift are including easily accessible data collection to evaluate the impact of the project to the neighbourhood after a short description of the project, specifying if it's involving a station or a district. The quality of transit is going to be defined by the distance, in meters, of the buildings by the closest high transit station; the walk ability is evaluated by the length of the walkways and their relationship with the blocks, if those are having opening or active life, from shading element, visuals and number of crossing lines; connectivity considers the dimension of the blocks (as percentage to the dimension of the station) and the number of crossing roads and pedestrian walkways; the mixed use is given by the percentage of residential areas within the buildings and the facilities offered by the station, the number of shops selling fresh food within a radius of 500 meters; density is given by the usual urban standards, with a specific note about number of workplaces and visitors included in the district; compactness is expressed in relation to the continuity of the built fronts, the number of further transit lines in the district besides the main station and eventual bike sharing system in place; shifting opportunities are expressed by the areas of the district, of the station, of different parking system, so as lanes and pedestrian transit. All these information clearly are not giving any qualitative evaluation of the district, nor actually evaluating the real accessibility, connectivity, and social fairness. The standards give a quantitative description without consider the qualitative result or interaction, as safety and largeness and actual accessibility of the walkways or decor of buildings. Based on the urban quality and the interconnection with the transportation is the evaluation system developed by the Transits Oriented Development Institute which confers start based on the level of achievement for each of the ten T.O.D. Principles.

Transit Oriented Development Institute (T.D.O.I.) on other hands defined the principles of T.O.D. as ten short description of the urban district: it should have the Station as core of the neighbourhood, possibly opening on a wide square; having well defined public spaces, considered as "outdoor rooms" in order to activate a human-scaled expression; offering a lively mix use of spaces; empowering the human scale and distances among daily uses; having and active ground floor with small retails, including cafes and sitting outdoor areas; tree lined and shaded streets; reduced and hidden parking; considering the affordability to different ranges of rent and property unit, so as dimensioning; constituting a model for further expansibility. The attention here is much more focused on the quality of the urban built environment for both buildings and open spaces, making of these principle a very good starting point for a more comprehensive evaluation of a T.O.D. The rating system applied by the T.O.D.I. is a one/two/three stars award for the projects, accordingly to their achievement of $6 / 8 / 10$ up to the 10 given criteria. 


\section{Conclusion}

The research shows the main differences between US and EU model for Transit Oriented Development where the European approach is more focused on central and dense built districts, creating an excellent model for rehabilitation processes in city centres all around the world; US cases, with their pragmatism can be better taken as case studies for expansion areas. and suburbs. The actual evaluation systems, elaborated by T.O.D.I. and I.T.P.D. shown the limit of being developed for real estate marketing strategies and with this a merely quantitative approach to the issue. Between the two the Guidelines of T.O.D.I. appears more related to urban quality and having some point in common with the UN goals for sustainable development. This deserve a further attention and steps of research.

\section{References}

[1] M. Castells, The Rise of the Network Society. Oxford: Blackwell, 1996.

[2] R. Cervero, The Transit Metropolis: A Global Inquiry. Washington DC: Island Press.Cervero, R. ed., 2004 TransitOriented Development in the United States: Experiences, Challenges and Prospects. TCRP Report 102, Washington DC, 1998.

[3] R. Cervero, Public transport and sustainable urbanism: global lessons, in Curtis. C., Renne, J. and Bertolini, L. eds., 2009.

[4] C. Curtis, J. Renne, and L. Bertolini, eds., Transit-Oriented Development: Making It Happen, 2009.

[5] S. Clark, B. Muthén, "Relating latent class analysis results to variables not included in the analysis," 2009. [Online]. Available: http://www.statmodel.com/download/relatinglca.pdf

[6] L. Bertolini, "Station areas as nodes and places in urban networks: An analytical tool and alternative development strategies," in Bruinsma et al. eds., Railway Development: Impacts on Urban Dynamics, Physica-Verlag, a Springer Company, 2008.

[7] P. Calthorpe, The Next American Metropolis: Ecology, Community, and the American Dream. Princeton: Princeton, Architectural Press, 1993.

[8] M. Hajer, “Zero friction society,” Urban Design Quarterly, vol. 71, pp. 29-34, 1999.

[9] C. Leinberger, The Option of Urbanism, 2009.

[10] R. Roger, Cities for a Small Planet. London: Faber and Faber, 1997.

[11] Transit-Oriented Development: Making It Happen. Aldershot: Ashgate, pp. 23-35.

[12] R. Lang, and P. K. Knox, "The new metropolis: rethinking megalopolis," Regional Studies, vol. 43, no. 6, pp. 789$802,2009$.

[13] W. Salet, and E. Gualini, Framing Strategic Urban Projects: Learning from Current Experiences in European Urban Regions. London: Routledge, 2006.

[14] W. Salet, and A. Thornley, "Institutional influences on the integration of multilevel governance and spatial policy in European city-regions," Journal of Planning Education and Research, vol. 27, no. 2, pp. 188-198, 2007.

[15] The European High-speed Train-network and Urban Development: Experiences in Fourteen European Urban Regions. Aldershot: Ashgate.

[16] D. Van Vliet, "Development/demonstration: an adaptive strategy," in Williams, K., Burton, E. and Jencks, M. eds. Achieving Sustainable Urban Form. London: E \& FN Spon, pp. 189-201, 2000.

[17] S. Majoor, Disconnected Innovations. New Urbanity in Large-Scale Development Projects. Delft: Eburon, 2008.

[18] S. Marvin, and S. Guy, eds., "Policy forum. Towards a new logic of transport planning?," Town Planning Review, vol. 70, no. 2, pp. 139-158, 1999.

[19] F. Moulaert, E. Salin, and T. Werquin, "Euralille - large-scale urban development and social polarization," European Urban and Regional Studies, vol. 8, no. 2, pp. 145-160, 2001.

[20] M. Neuman, "Multi-scalar large institutional networks in regional planning," Planning Theory and Practice, vol. 8, pp. 319-344, 2007.

[21] P. Newman, Planning for transit oriented development: strategic principles, in Curtis, C., 2009.

[22] J. Renne, and L. Bertolini, eds., Transit-Oriented Development: Making It Happen. Aldershot, Ashgate, pp. 13-22.

[23] P. Newman, and A. Thornley, "Euralille: 'Boosterism' at the centre of Europe," European and Regional Studies, vol. 2, no. 3, pp. 237-246, 1995. 
[24] S. Graham, and S. Marvin, Splintering Urbanism. Networked Infrastructures, Technological Motilities and the Urban Condition. London: Routledge, 2001

[25] M. De Jong, "Attractiveness of HST Locations: Eight Cases in Northwest Europe," M.S. Thesis, University of Amsterdam, 2007.

[26] R. Cervero, M. Duncan, "Transit's Value Added," Urban Land, vol. 61, no. 2, pp. 77-84, 2002.

[27] R. Cervero, C. Ferrell, C. Murphy, "Transit-Oriented Development and Joint Development in the United States: A Literature Review," TCRP Project H-27, Research Results Digest October 2002, no. 52, 2002.

[28] C. Atkinson-Palombo, "Comparing the capitalisation benefits of light-rail transit and overlay zoning for singlefamily houses and condos by neighbourhood type in metropolitan Phoenix, Arizona," Urban Studies, vol. 47, no. 11, pp. 2409-2426, 2010

[29] K. Bartholomew, R. Ewing, "Hedonic price effects of pedestrian- and transit-oriented development," Journal of Planning Literature, vol. 26, no. 1, pp. 18-34, 2011.

[30] R. Cervero, S. Murphy, C. Ferrell, "Transit-oriented development in the United States: Experiences, challenges, and prospects," Report No. 102, Washington, DC: Transit Cooperative Research Program on Google Scholar, 2004.

[31] Ministry of Housing, Spatial Planning and the Environment (undated) New Key Projects: The Station as a Gateway to the City. The Hague: Ministry of Housing, Spatial Planning and the Environment. [Online]. Available: www.vrom.nl/international. 